\title{
Evaluation of the Efficiency of the Micro-irrigation Systems in Gardens of Chaharmahal and Bakhtiari Province of Iran
}

\author{
Rahim Alimohammadi Nafchi \\ Agricultural Engineering Research Department, Chaharmahal and Bakhtiari Agricultural and Natural Resources Research and Education \\ Center, AREEO, Shahrekord, Iran
}

Email address:

nafchi38@gmail.com

\section{To cite this article:}

Rahim Alimohammadi Nafchi. Evaluation of the Efficiency of the Micro-irrigation Systems in Gardens of Chaharmahal and Bakhtiari Province of Iran. International Journal of Agricultural Economics. Vol. 6, No. 3, 2021, pp. 106-110. doi: 10.11648/j.ijae.20210603.12

Received: March 29, 2021; Accepted: May 25, 2021; Published: May 31, 2021

\begin{abstract}
The supply of food security of the society requires the stability of the water resources, that's requiring the management of optimal water consumption. For this purpose, a research project was conducted to evaluate the efficiency and improvement of optimal water consumption in the gardens of Chaharmahal and Bakhtiari Province. After identifying microirrigation plans in the province, 16 plans were selected randomly in different climates and levels. The evaluation indexes were selected based on the instruction of the U.S. Soil Conservation Service (SCS) and American Society of Civil Engineers (ASCE). Parameters of the absolute emission uniformity (EU), the statistical uniformity of Coefficient (Us), efficiency reduction factor (ERF), and flow rate coefficient of variations were obtained. The results indicated that 43.7 percent of the projects being studied had a very good statistical emission uniformity and 31.3 percent showed a Poor and average statistical emission uniformity and 25 percent of the projects had an unacceptable statistical emission uniformity. The flow rate nonuniformity of the droppers and the resulting low coefficients indicated the manipulation of the droppers. The average ERF is 0.717 in the selected projects, which is due to the non-supply of the pressure required in the irrigation systems. The dependence of the Farmers and agricultural operators on government's aids is one of the main challenges and obstacles of the growth of agriculture and stable productivity in the region.
\end{abstract}

Keywords: Drip Irrigation Systems, Evaluation Indexes, Food Security, Stable Optimal Management of Irrigation

\section{Introduction}

Water is the axis of development and the alphabet of sustainable food security in different societies, especially in arid and semi-arid regions. Agricultural and horticultural products have an important role in the supply of food security of the society. Due to the challenges caused of water scarcity, the agricultural sector needs to increase the efficiency and productivity of water consumption as much as possible. For this purpose, the development and optimal use of micro irrigation systems due to their high efficiency, are a logical, principled and sustainable solution worldwide. These systems required the sufficient training and skills of farmers (beneficiaries) and this is a mutual approach [1]. In the drip irrigation systems, if management, economic and finally water efficiency management are observed, the best result is achieved [2]. The drip irrigation systems are a suitable solution to irrigate and confront the water deficiency in arid and semi-arid regions, and the increase in the productivity in the micro-irrigation systems requires the application of special conditions of systems and following their technical and hydraulic issues accurately [3]. A significant difference was observed in the evaluation of different irrigation systems in an apple garden using the imaging system at the University of Idaho Parma Research and Extension Center in Parma, Idaho, (Idaho University) among different treatments based on the vegetation indices [4]. The main problems of the drip irrigation systems in the northern Iran are related to the design, implementation and management issues; and EU, ERF, potential application efficiency of low quarter (PELQ) and application efficiency of low quarter (AELQ) values have been 79, 90, 65 and $73 \%$, respectively, showing the medium condition of the irrigation systems in the region [5]. The average indices of EU, ERF, PELQ and AELQ measured in the drip irrigation systems in the western Iran were equivalent to (43.4 to 
$65.7),(0.8$ to 6.3$),(39.1$ to 59.1$)$ and (34 to 73$) \%$, and the reasons of the low indices include the unsuitable design, difference in design and implementation, inaccuracy in the control and pressure setting, application of unsuitable connections and appliances, weakness in management and inadequate information of the producers [6]. The most important problems of the drip irrigation systems in the gardens in the northern Iran include the obstruction of droppers, non-supply of the necessary pressure and flow rate. Coefficients of variations and EU were 7.1 and $91 \%$, variations of emission uniformity ranged from 68 to $91 \%$, potential and actual application efficiency ranged from (61 to $82 \%$ ) and (561 to $85 \%$ ) in the region [7]. The average values of the coefficients CU, EU, PELQ and AELQ were $95.12,91.68,82.91$ and $91.2 \%$, respectively, showing the suitable management and design of the irrigation systems being examined in Shahid Rajaei center of cultivation and industry, Dezfoul [8]. If micro-irrigation systems are equipped with the control systems to adjust the pressure and flow rate, they will have more productivity [9]. Issues and challenges related to water resources management in farming increase everyday more than before and in this regard, dynamism and active management of water cycle are especially important, because water resources management is one of the main issues and challenges of farming water [10]. Most researchers have concluded that the selection of the type of droppers is very important in terms of the quality of the irrigation water and the climate of the region, training the farmers before the system implementation, Level of farmers education, good design and intelligent control of the farm, especially the accurate control of the pressure and flow rate. And if irrigation management is performed uniquely and in an integrated way in the farms, the efficiency and productivity of water consumption will be increased. And uniformity in microirrigation systems is a function of the droppers' flow rate, dimensions of laterals and the network pressure. Therefore, it was necessary to perform this project and evaluated the projects implemented to solve their problems and defects and increase water consumption efficiency and productivity.

\section{Materials and Methods}

This research was conducted in Chaharmahal and Bakhtiari Province, Iran, with the geographic position 31 degrees and $9 \mathrm{~min}$ to 32 degrees and $48 \mathrm{~min}$ northern latitude, and also 49 degrees and $28 \mathrm{~min}$ to 51 degrees and $25 \mathrm{~min}$ eastern longitude. The maximum area of gardens under cultivation and the drip irrigation systems are located around Saman agricultural meteorological complementary synoptic station with the average daily temperature 13.3 ${ }^{\circ} \mathrm{C}$, relative humidity $36.5 \%$, annual rainfall $329.3 \mathrm{~mm}$ and annual evaporation $2386 \mathrm{~mm}$. The soil texture is different in various regions and is usually a light to semiheavy texture. 16 projects were selected randomly among the irrigation systems implemented according to the area under cultivation (areas less than 2 ha, (2-5) ha, (5-10) ha,
(10 to 20$)$ ha, (20 to 50 ) ha and more than 50 ha). The parameters including pressure, inlet flow rate, and flow rate of droppers were measured and complemented based on ASAE Standard and the instruction of U.S. Soil Conservation Service (SCS) and the examination of filtration and completion of the questionnaire before the producers. One working manifold was selected randomly and 4 laterals (elementary, 1/3, 2/3 and final) were selected and over any lateral, 4 elementary parts, $1 / 3,2 / 3$ and final parts were determined; then, the volume of the outlet water of its two droppers was measured for $5 \mathrm{~min}$. The pressure values were also measured at the beginning and end of any lateral being tested. Measuring 32 flow rates and 8 pressures at any system, the evaluation indices were obtained and the performance of the systems was evaluated [11]. The collected data were used to evaluate the indices including uniformity coefficient, EU, emitter discharge coefficient of variations of droppers and statistical flow rate uniformity. The emitter discharge coefficient of variations is employed to measure the distribution of the statistical data and shows the level of distribution per one unit of average (Equation 1) [12].

$$
\begin{gathered}
C_{v}=\frac{1}{q_{\text {ave }}}\left(\sqrt{\frac{\left(q_{i}-q_{\text {ave }}\right)^{2}}{n-1}}\right) \\
q_{\text {ave }}=\frac{\sum_{i=1}^{n} q_{i}}{n}
\end{gathered}
$$

US the statistical uniformity of water application

$$
U S=100 \times\left(1-\frac{\sqrt{\frac{\left(q_{i}-q_{\text {ave }}\right)^{2}}{n-1}}}{q_{\text {ave }}}\right)
$$

Emission uniformity (EU), emission uniformity efficiency, depends on the uniformity of the watering of droppers in the system and shows the difference between the minimum and average watering in the micro-irrigation network [13].

$$
E_{u}=\left(\left(1-1.27 \times \frac{C_{v}}{\sqrt{e}}\right) \times \frac{q_{n}}{q_{\text {ave }}}\right) \times 100
$$

$\mathrm{q}_{\text {ave }}$ Average flow rate of total emitters $(\mathrm{L} / \mathrm{h})$.

$\mathrm{q}_{\mathrm{i}}$ Flow rate of each dropper (liters per hour)

e Number of droppers for each tree

$\mathrm{Cv}$ Emitter discharge coefficient of variation.

$\mathrm{q}_{\mathrm{n}}$ Minimum flow rate of droppers with minimum pressure extracted of the flow rate-pressure relationship curve (liters per hour).

$\mathrm{q}_{\mathrm{rn}}$ Average flow rate of 25 percent of sample droppers that under a certain pressure, their flow rate is less than all (liters per hour).

Efficiency Reduction Factor (ERF)

$$
E R F=\frac{1.5 M L I P_{\min }+M L I P_{\text {ave }}}{2.5 M L I P_{\text {ave }}}
$$

MLIP $_{\text {min }}$ Minimum lateral inlet pressure (meter) MLIP $_{\text {ave }}$ Average lateral inlet pressure (meter). The statistical analysis was done using SPSS Software. 


\section{Results}

The average flow rate of the droppers, the statistical uniformity coefficient and the emission uniformity of water of the systems are offered in table 2 . The results indicated that $43.7 \%$ of the plans being studied had a good statistical emission uniformity, $31.3 \%$ had a weak average statistical emission uniformity and finally, $25 \%$ of the plans had an unacceptable statistical emission uniformity. The minimum average flow rate of droppers is 4.07 litre per hour in the project no. 11 and is at most 179.5 litre per hour in the project no. 9 (General Yasehchah). But the average of $25 \%$ of the minimum flow rate of droppers in plan number 8 was less than 3 liters per hour and the maximum value was 125.24 liters per hour in plan number 12 . The outlet uniformity of the droppers was maximum $(90.3 \%)$ in the plan no. 16 and it was minimum $(28.4 \%)$ in the project no. 11 . The internal efficiency of the systems was maximum in the projects no. 16 and 13 , and was minimum (28.4\%) in the project no. 11 (table 2).

Table 1. System classification according to Us [14] and EU [15].

\begin{tabular}{lll}
\hline Description & Us (\%) & EU (\%) \\
\hline Excellent & $>90$ & $>90$ \\
Very Good & $80-89$ & $80-90$ \\
Acceptable & $70-80$ & $70-80$ \\
Poor & $60-70$ & $66-70$ \\
Unacceptable & $<60$ & $<66$ \\
\hline
\end{tabular}

Table 2. Measured values of dripper discharge and estimation of a few evaluation indexes separately for each farm.

\begin{tabular}{lllll}
\hline No. of Projects & $\bar{q} \mathbf{L i t} / \mathbf{h r}$ & $\mathbf{C v}$ & $\mathbf{E U}$ & $\mathbf{U s}$ \\
\hline 1 & 9.48 & 25.31 & 81.20 & 47.7 \\
2 & 39.41 & 24.89 & 63.31 & 75.11 \\
3 & 43.25 & 36.04 & 62.69 & 63.69 \\
4 & 80.48 & 36.17 & 66.50 & 63.82 \\
5 & 17.77 & 81.65 & 25.47 & 18.35 \\
6 & 62.65 & 45.14 & 54.04 & 54.86 \\
7 & 81.74 & 54.43 & 48.42 & 45.57 \\
8 & 4.26 & 36.15 & 68.16 & 63.85 \\
9 & 179.5 & 39.42 & 62.07 & 60.58 \\
10 & 21.53 & 33.36 & 81.59 & 66.64 \\
11 & 4.07 & 15.99 & 86.92 & 84.01 \\
12 & 146.32 & 17.94 & 88.35 & 82.06 \\
13 & 4.93 & 11.36 & 91.22 & 88.64 \\
14 & 100.51 & 55.27 & 57.56 & 44.73 \\
15 & 4.64 & 29.52 & 89.17 & 70.48 \\
16 & 4.64 & 9.30 & 92.54 & 90.70 \\
\hline
\end{tabular}

The values of the coefficient of variations of the droppers in the plans being studied offered in table 2 indicate that most of the calculated coefficients are more than the normal limit for the following reasons:

Discharge of the contents inside the droppers

Exchanging the droppers and making them adjustable with more watering

Diversity in the droppers for the reasons mentioned above and since the producers mostly want to do irrigation and don't believe irrigation with a unique integrated management. For this reason, they think that the irrigation plan offered by the consulting engineers companies is not implementable. This issue has decreased the irrigation time (water fees) and has increased the inlet flow rate.
Exchanging or manipulating the droppers, has decreased the irrigation time, increased the discharge of droppers, and pressure decline in the systems, and this issue has resulted in the dissatisfaction of the producers and the change in the diameter of the lateral pipe, etc.

The obstruction of the droppers due to the presence of algae in the systems (low depth and large surface of the pools) and removing the central control system from the orbit and sometimes, the inefficiency of the central control systems is due to using a similar prescription for all.

Cultivating peach trees between almond tress because peach is harvestable sooner, and the severe changes in their water need have disrupted the plans and have made the producers dissatisfied.

The economic instability, the increase in prices, and weakness in the supervision of the governing bodies are the factors of using low quality connections and appliances, especially the droppers.

Other problems include their inadequate information on the distribution of the water moisture front in soil and the way water is absorbed around the root and the weak supervision on the distribution of water in the farms. Quick growth and production of algae and the presence of the soluble and sometimes suspending salts in water have deposited in the droppers. Importantly, the changes in the pressure (pressure decrease) in the system double the obstruction problems. Due to the special topography of the province, the rivers and water reservoirs that are in the thalwegs and the location of gardens on the hills around the water resources, using one or multiple stage pumping systems is very popular. In some plans, the pumped water directly enters the network and in some other plans, it first enters the water storing pool located on the heights higher than the network and then, it enters and is distributed in the system. One of the tasks of the pools includes creating a balance between the supply (the pumped flow rate) and the demand (the required flow rate of the plan). In any irrigation unit, the pressure was mostly adjustable by the riser valve (at the beginning of the manifold). Now, if the inlet manifold pressure is not adjusted correctly, the total efficiency of the system becomes less than the efficiency of the manifold being tested. It is worthy to note that in most systems, producers have manipulated the droppers in a way that the droppers can discharge a flow rate that is several times more than the standard flow rate. The issues mentioned above are due to the inadequate information and familiarity of the producers with the utilization of the systems and the economic issues of the plans. The average pressure is minimum ( 0.22 bar $)$ in the plan no. 11 and is maximum (3.16 bar) in the plan no. 13. The pressure was minimum $(0.1$ bar $)$ in the plans no. 7,11 and 15 , and was maximum (1.92 bar) in the plan no. 16. Figure 1 shows the efficiency reduction factor (ERF), and the effect and interference of the producing manager with the control of the pressure at the beginning of the irrigation blocks. The calculated minimum, maximum and average values are 0.49 , 0.97 and 0.717 , respectively (figure 1). The decrease in ERF is due to the manipulation of the valves at the beginning of the irrigating manifolds and also the low outlet pressure of the 
pumping station and the problems of the central control station. To calculate the ERF, the minimum inlet pressure of the laterals in the system is used. This index shows pressure adjustment at the beginning of the working manifolds. The closer the index value to one, the better the adjustments are (Ghasemzadeh Mojaveri, 1990).

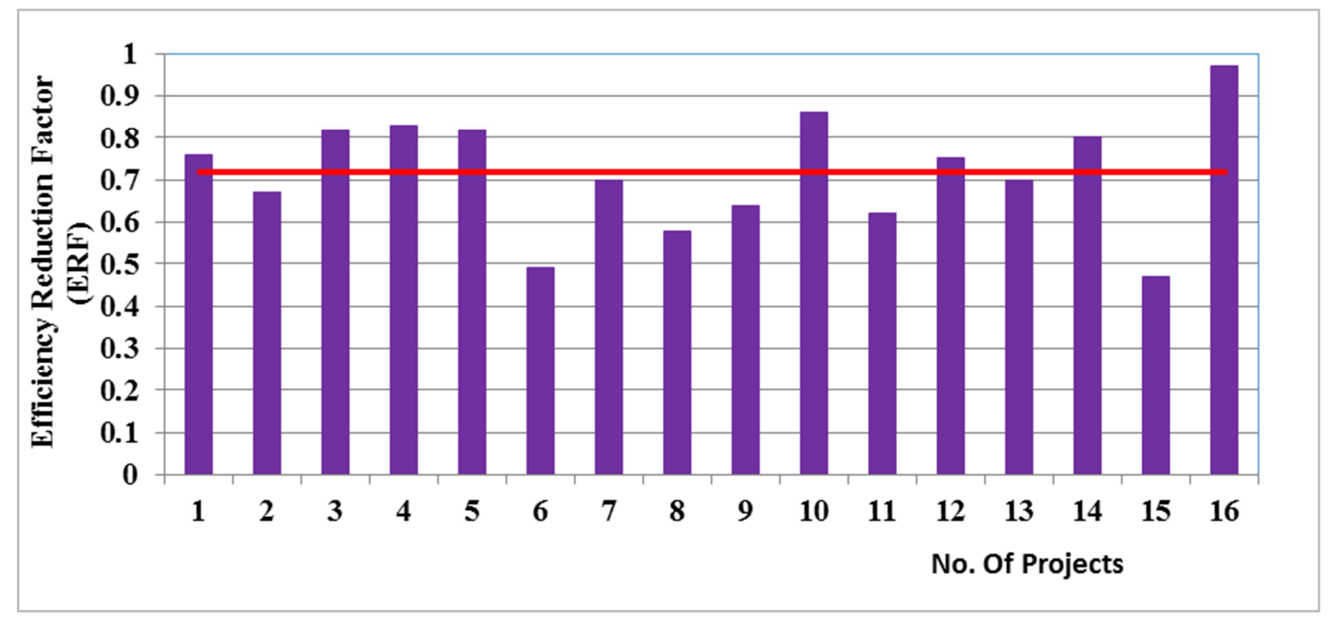

Figure 1. Efficiency Reduction Factor in Different Irrigation systems (Drop).

In figure 2, the values of the designed and used water are compared with each other. The sharp changes in the amount of water used are due to the age of trees and different water needs, water fees of producers, not following the presented irrigation programs and cooperatives by the producers, manipulation of most droppers and cultivation of different species in a plot without informing the designer, and this issue has disrupted the whole system design. Another noteworthy point is that the applicants of micro-irrigation systems are not actual gardeners, but they are unemployed people whose main job cannot be gardening and farming, and due to their temporary job or their second job, they have bought lands, planted seedlings and implemented an imposed system, or they are people who do this to possess national lands or for the sake of the added values of the lands. In any case, the lack of actual desire of producers is rooted in this issue, and the implementation of micro-irrigation systems is imposed on them due to the assignment of lands, taking loans and government aids.

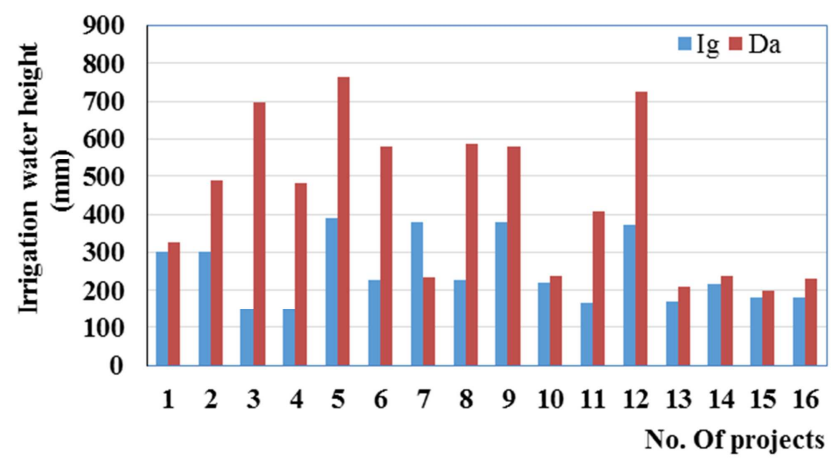

Figure 2. Amounts of water Designed (Ig) and Applied (Da) in selected projects (mm/year).

\section{Discussion and Conclusions}

The amount of water used was more than the predicted water (designed amount) and the required water of the systems, because most farmers have not information enough on the utilization of micro irrigation system. Farmers have mostly implementing micro-irrigation systems in the area to obtaining land, loans, and water harvesting permits. Manipulation and replacement of emitters with high flow rate, cultivation of fast yielding trees between the main trees and increasing the number and discharge of emitters are the main causes of disruption of flow rate and pressure in the systems were have caused general dissatisfaction. That usually results in public dissatisfaction and naturally, as dissatisfaction increased, the diameter of the pipes have changed in different parts of the plan and additional costs have been imposed on the plan. So, if before the implementation of the micro-irrigation system, the producers are trained well and they obtain the required information on the water distribution and absorption in soil, performance and efficiency of the system and droppers, naturally, the acceptance rate of unique integrated irrigation management will increase significantly in the plans. The correct use of micro-irrigation systems is possible by applying an integrated management related to the compliance of a suitable cultivation pattern, issues related to planting to harvesting and the stage after harvesting the crops by applying and observing water consumption management exactly based on a scientific program and having the capability of the calculated and presented implementation.

\section{References}

[1] Pandya, Er. A. B., 2018. Capacity development for promoting micro irrigation systems missing communication. Irrigation and drainage, 67: 625-626.

[2] Woltering, L., Ibrahim, A., Pasternak, D. and ndjenga, J. (2011). The economic of low pressure drip irrigation and hand watering for vegetable production in the Sahel. Agricultural water management, 99 (1): 67-73. 
[3] Kooji, S. V., Zwarteveen, M., Boesveld, H., and Kuper, M. (2013). The efficiency of drip irrigation unpacked. Agricultural water management, 123 (31): 103-110.

[4] Bulanon, D. M., Lonai, J., Skovgard, H., and Fallahi, E. 2016. Evaluation of Different Irrigation Methods for an Apple Orchard Using an Aerial Imaging System. International journal of geo- Information, 5 (79): 2-11.

[5] Shaker, M., Hesam, M., Kiani A. R., and Zakeri Nia, M. 2014. Technical evaluation of implemented drip irrigation systems in the gardens of Golestan Province. Journal of Water and Soil Conservation, 21 (4): 261-274.

[6] Zare Abyaneh, H., Danaii, A., Akhavan, S., and Jovzi, M. 2020. Performance Evaluation of New Irrigation Systems in Hamedan. Journal of water irrigation management, 10 (3): 381-395.

[7] Ramzanian Azizi, n., Yasari e., and Kakularimi, a. (2013). Evaluation of Drip Irrigation in the Province of Mazandaran of Northern Iran a Case Study on the City of Babol. International Journal of Agriculture and Crop Sciences, 6 (9): $522-528$.

[8] Ashiri, M., Boroomand-Nasab, S. and Hooshmand, A. (2014). Technical Evaluation of Drip Irrigation Systems (Case Study of Shahid Rajaayi Agro-Industry - Dezful). World Rural Observations 6 (3): 36-43.
[9] Momvandi, A. Omidi Najafabadi, M., Hosseini, J. F. and Lashgarara, F. 2019. Factors affecting the tendency of Iranian Farms to use Pressurized irrigation systems. Strategic research journal of agricultural Sciences and natural resources, 4 (2): 223-238.

[10] Pereira, L. S. 2017. Water, Agriculture and Food: Challenges and Issues. Water Resources Management, 1-15. DOI 10.1007/s11269-017-1664-z,

https:/www.researchgate.net/publication/317974239_Water_ Agriculture_and_Food_Challenges_and_Issues

[11] Ghasemzadeh Mojaveri, F., 1998. Assessment of farm irrigation systems. Astan Quds Razavi Publications. 336 pp.

[12] ASAE, 1996. American Society of Agricultural Engineers Standards; Test Procedure for Determining the Uniformity of Water Distribution of Center Pivot and Lateral Move; ASABE: St. Joseph, MI, USA.

[13] Keller, J. and Blisner, R. D. 1990. Sprinkler and trickle irrigation. Van Nostrand Rainbold, New York, 10003, pp: 642.

[14] ASAE, 2003. American Society of Agricultural Engineers Standards EP458; Field Evaluation of Micro Irrigation Systems; ASAE: St. Joseph, MI, USA; pp. 760-765.

[15] Merriam, J. L. and Keller, J. 1978. Farm Irrigation System Evaluation: A Guide to Management. Utah State University, Logan, Utah. 